\title{
Experiments in Objectively Predicting Some Atmospheric and Oceanic Variables for the Winter of 1971-72
}

\author{
Jerome Namias \\ Scripps Institution of Oceanography, La Jolla, Calif. 92037
}

(Manuscript received 7 June 1972, in revised form 11 July 1972)

\begin{abstract}
The oceanic and atmospheric anomalies of the winter of 1971-72, markedly different from those prevailing during the 1960 's, are described, analyzed, and subjected to experimental objective predictions. Seasurface temperature patterns over the North Pacific developed in such a slow, orderly fashion from fall 1971 to the following winter that a kinematic treatment successfully captured the evolution. Physical processes associated with this evolution are investigated and show that local air-sea heat exchange played a negligible role relative to water-mass transport around the North Pacific oceanic gyre.

The resulting winter sea-surface temperature pattern appeared to place demands on the overlying circulation, producing anomalous atmospheric flow patterns at sea level and aloft. A multiple-regression analysis based on 20 independent winters' data was successfully used to predict the probable winter 1971-72 sea-level pressure pattern from the observed fall 1971 sea-surface temperature pattern. Finally the winter 1971-72 regime is considered as a break with the prevailing state of the winters since 1958, posing the unanswered question of whether a new climatic regime is emerging for the 1970's.
\end{abstract}

\section{Introduction}

The winter of 1971-72 differed in many respects from the winters of the past 14 years. For example, winters over the coterminous United States during the years 1958-71 were predominantly colder than normal in the East but warmer than normal in the West (Namias, 1970a), while in the winter of 1971-72 this pattern was reversed. Fig. 1 illustrates the change of temperature regime as observed at Atlanta, Ga., a station with a homogeneous record and representative of the southeastern United States. Details of the weather charac- teristics for each month of the 1971-72 winter are given by Dickson (1972), Wagner (1972), and Taubensee (1972).

Contemporaneously, the sea-surface temperature (SST) patterns over the North Pacific underwent a radical change from those of the decade of the 1960's. Whereas these earlier winters were characterized by anomalously warm water off the West Coast of the United States and cold water in the central Pacific, the winter of 1971-72 was characterized by cold water off the west coast and warm water in the east central North

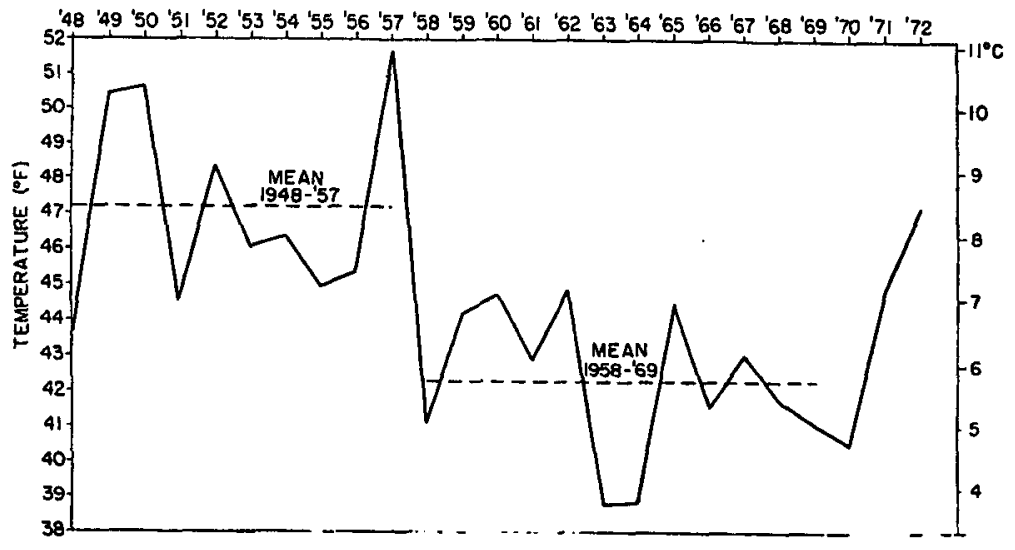

Fig. 1. Winter mean temperatures at Atlanta, Ga.

1 Presented at the Fourth Conference on Weather Forecasting and Analysis, 1-4 May 1972, Portland, Orc. 


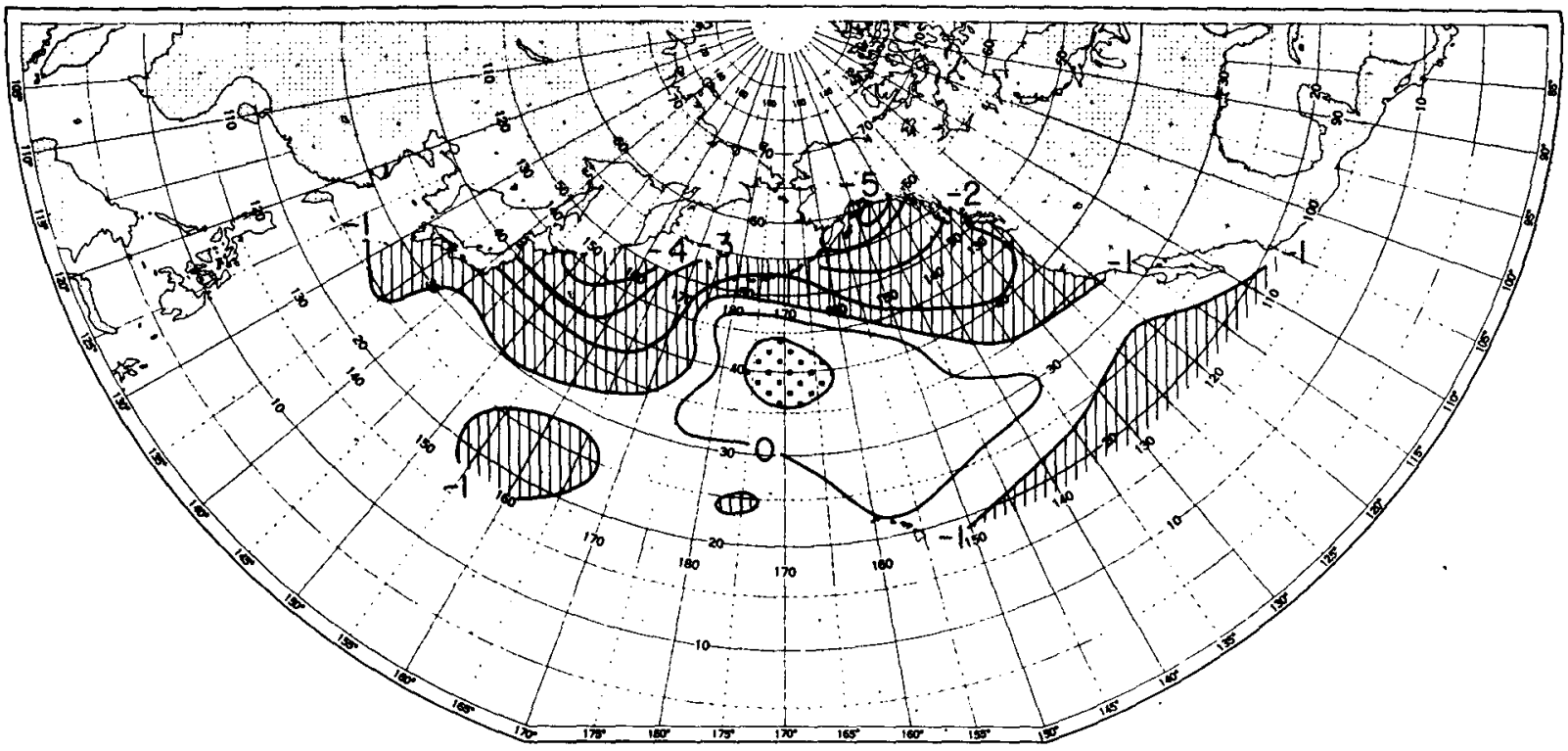

FIg. 2. Fall 1971 sea-surface temperature departure $\left({ }^{\circ} \mathrm{F}\right)$ from the 20 -year mean 1947-66. Areas less than $-1 \mathrm{~F}$ are hatched; areas greater than $+1 \mathrm{~F}$ are stippled.

Pacific. A detailed description of the large-scale North Pacific SST patterns and atmospheric flow patterns during the winter periods from 1958-70 has been given by Namias (1972).

It is the purpose of this paper to interrelate the largescale SST and atmospheric flow patterns leading up to and including those for winter 1971-72 and to describe simple model experiments which seem to have captured the evolution of both sea and air patterns.

While the starting point of any discussion on air-sea interaction is arbitrary, we shall begin with the North
Pacific SST patterns, in part because the conclusion of this paper (as well as of earlier work by the author) is that long-range weather forecasting may hinge upon knowledge of SST patterns.

\section{SST anomalies in the North Pacific}

Deviations of fall 1971 and winter 1971-72 SST from 20-year (1947-66) averages computed for $5^{\circ}$ squares are shown in Figs. 2 and 3, and the fall-to-winter change in anomalies in Fig. 4. Prominent in these figures is the eastward motion (about $18^{\circ}$ of longitude) and inten-

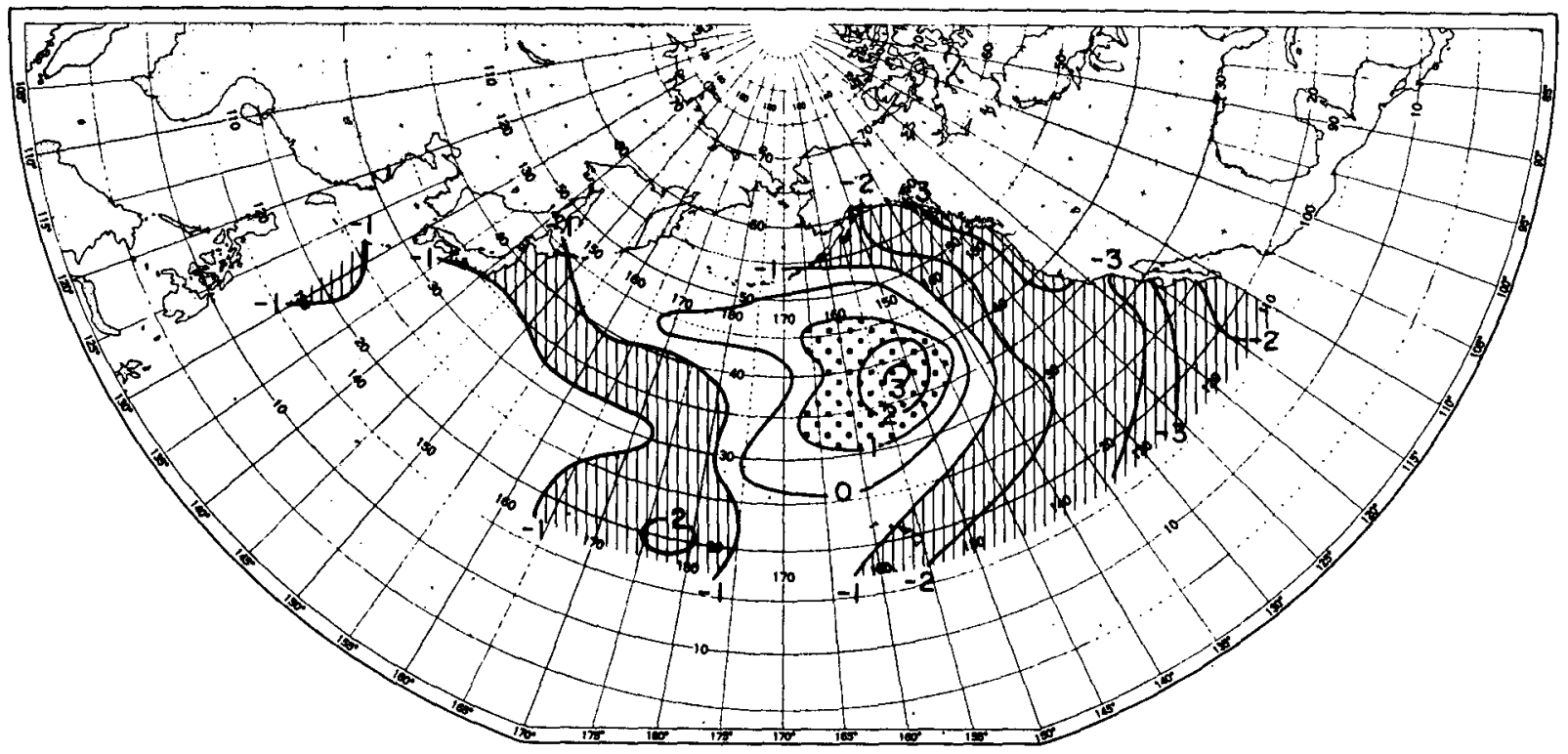

FIG. 3. Winter 1971-72 sea-surface temperature departure $\left({ }^{\circ} \mathrm{F}\right)$ from the 20 -year mean 1947-66. Shading as in Fig. 2. 


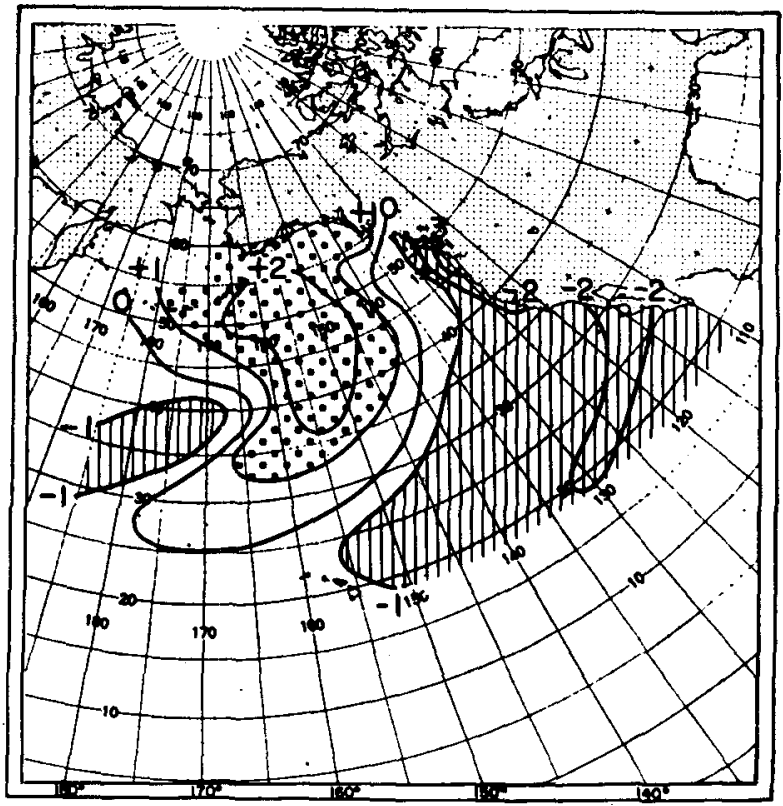

Iis. 4. Change in sea-surface temperature anomalies from fall 1971 to winter 1971-72. Shading as in Fig. 2.

sification of the central warm pool and the extension of anomalously cool water from the west coast toward Hawaii. The evolution of the winter SST pattern seems to have been an orderly and gradual process as indicated by month-to-month SST anomaly charts (not reproduced). For example, the changes in SST anomaly at three representative points are shown in Fig. 5.
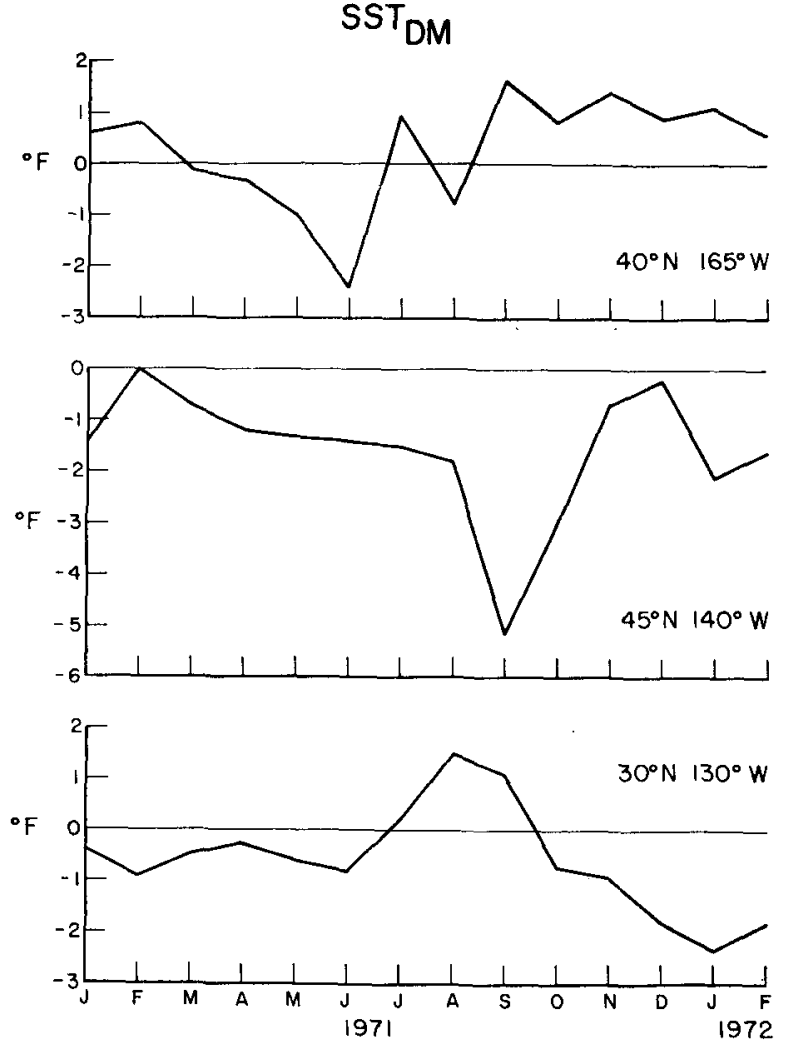

FIG. 5. Monthly-mean sea-surface temperature anomalies.

(These points are shown by crossed circles in Fig. 8.) Note that an anomalous warming trend began as early as June 1971 at $40 \mathrm{~N}, 165 \mathrm{~W}$, but was delayed until

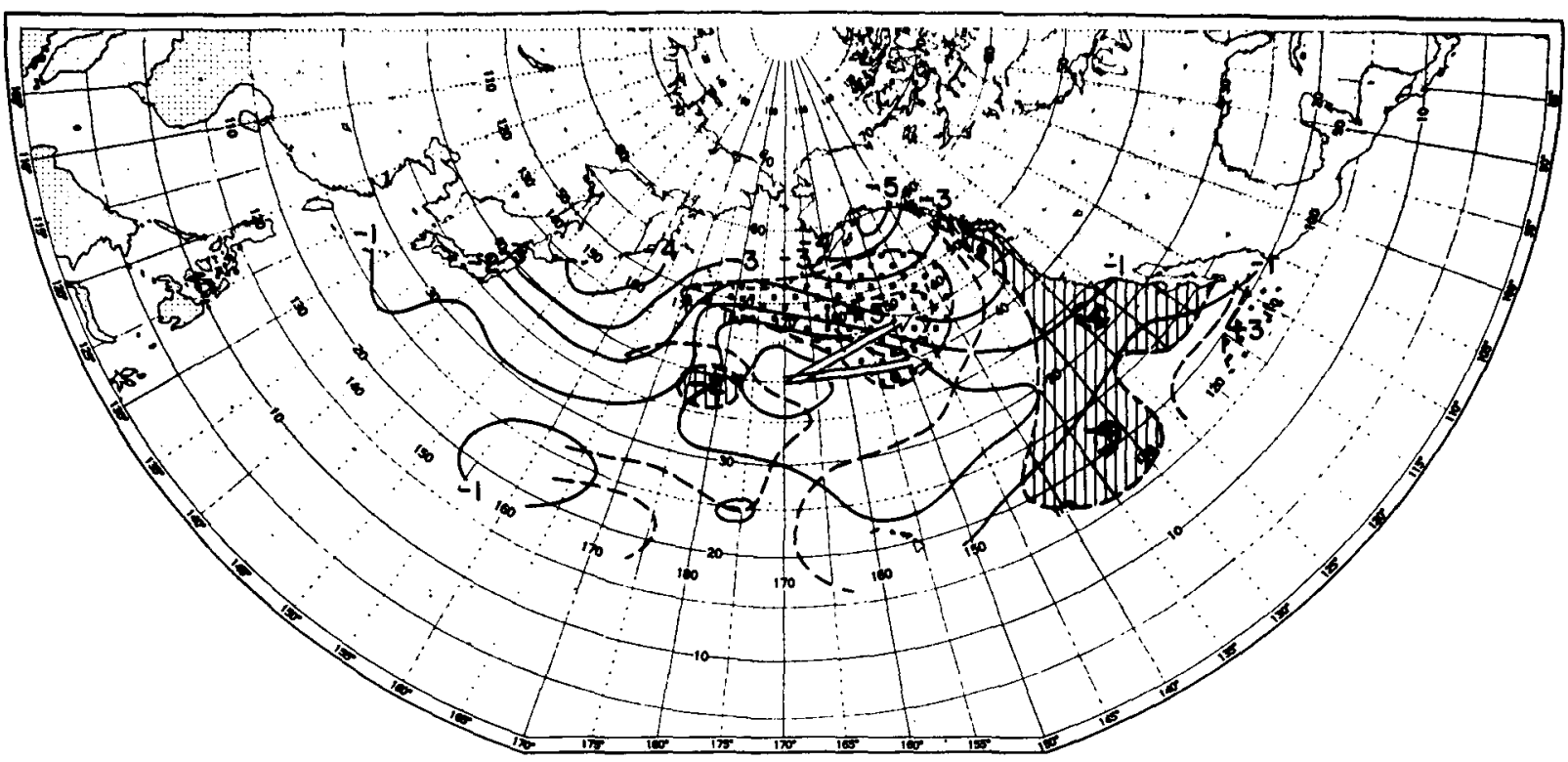

Fig. 6. Kinematic chart and computations centered on fall 1971. Solid lines are isopleths of the three-month sea-surface temperature anomalies. Broken lines are isopleths of difference between September and November anomalies. Tendency iospleths drawn for $2 \mathrm{~F}$ intervals. Hatching and stippling for tendencies exceeding $\pm 2 F$. Arrows show kinematic three-month displacement of center of warm pool. 
September at $45 \mathrm{~N}, 140 \mathrm{~W}$, when anomalous cooling began to set in at $30 \mathrm{~N}, 130 \mathrm{~W}$.

The apparent regularity of evolution of the SST pattern from autumn to winter suggested that a kinematic treatment might be revealing. Therefore, a fallseason tendency, the November minus September differences in SST anomaly, were superimposed on the mean SST pattern for fall as shown in Fig. 6. From the isopleths of this two-month tendency and the autumn field of SST anomaly, displacements for singular features, such as the warm pool, can be computed, just as is done with pressure and pressure-tendency fields in synoptic meteorology (Petterssen, 1956). The arrows in Fig. 6 represent one such kinematic computation; the arrows give the net three-month displacement and also the zonal component of displacement of the warm pool assuming no acceleration. The computed position for the warm pool agrees quite well with the observed (Fig. 3). Note especially that the tendency field generated in fall remained remarkably similar from fall to the subsequent winter (Fig. 4). Thus, fall 1971 contained important prognostic information for determining the ensuing winter 1971-72 SST pattern. While this kinematic treatment highlights the slowly evolving trend, it does not tell why such an evolution occurred. To get at the latter problem I have examined the relative importance of heat exchange and advection as described below.

\section{Physical causes of the winter SST anomalies}

The National Marine Fisheries Service's Laboratory at La Jolla routinely computes monthly components of the air-sea heat exchange by the method of Johnson et al. (1965), which takes account of latent and sensible heat losses, insolation, and back radiation. Members of the Laboratory kindly furnished December 1971 through February 1972 values of the net heat exchange $Q$ and its anomaly. Using these values of $Q, Y$ computed the anomalous loss or gain of heat across the surface for the winter season. Corresponding sea-surface temperature anomalies were then calculated by assuming a uniform temperature change to the depth of the mixed layer. Because of lack of data on the actual depths of the mixed layer during the winter of 1971-72, an approximation was made that these depths were taken to be equal to the climatological normal recently determined by Robinson and Bauer (1971). Over most of the area from $180^{\circ}$ eastward to $120 \mathrm{~W}$ and north of $20 \mathrm{~N}$, the average wintertime mixed layer is about $100 \mathrm{~m}$ diminishing to less than $60 \mathrm{~m}$ off the California coast.

Results of these heat exchange computations, expressed in terms of the resulting anomaly in temperature, are shown in Fig. 7. Comparing the computed with the observed winter SST anomalies (Figs. 7 and 3), it is obvious that advection and changes in mixed-layer depth must have played important roles. This is especially true in the vicinity of the observed warm poot

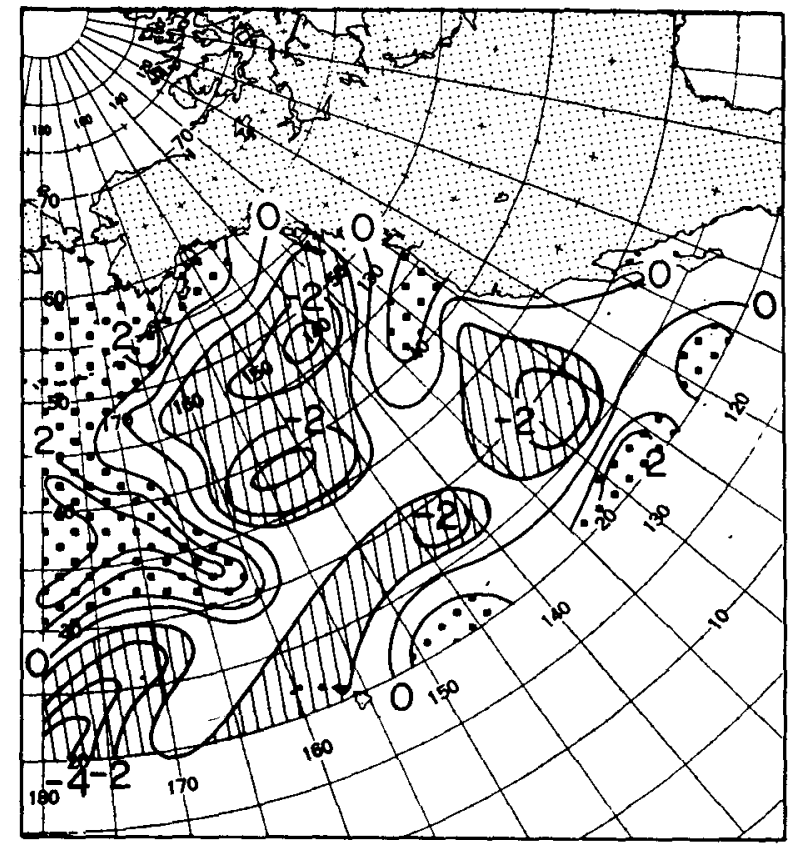

FIG. 7. Changes $\left({ }^{\circ} \mathrm{F}\right)$ in sea-surface temperature anomalies of the mixed layer due to air-sea heat exchange during winter 1971-72. Shading same as Fig. 2.

where the calculations suggest a heat loss from the water, and also between latitudes 30 and $40 \mathrm{~N}$ from $160 \mathrm{~W}$ to $180^{\circ}$ and in other areas where the signs of the anomaly are opposed. On the other hand, some of the observed cooling between Hawaii and California and also at $20 \mathrm{~N}, 180^{\circ}$ seems to agree with the heat $\mathrm{ex}^{-}$ change computations.

Unfortunately, lack of data on observed mixed-layer depths makes it impossible to analyze this aspect. However, we shall see that advection appears dominant. Since the isopleths of SST anomaly were in many areas orthogonal to the mean currents of the North Pacific gyre, an experiment was performed on the assumption that the SST anomaly for each oceanic parcel was conserved and simply carried along with the mean current. The carrying current was the climatological mean from a detailed version of Fig. 8, and this was applied to the SST anomaly of Fig. 2. Although at first glance this appears to be a rather naive assumption, it may serve as a first approximation to the advective change if seasonal changes proceed in a normal fashion and if the anomaly patterns are strong and contain large spatiallycoherent areas. At least the latter contingency applies in our case (see Figs. 2 and 3). The initial SST anomaly chart for fall was transcribed into the format shown in Fig. 9a and forecasts of the new SST anomaly pattern were generated at intervals of 15 days up to one season (90 days). The results of the 30-day iterations are displayed in Figs. 9b, c and d.

These results show 1) the eastward migration of the warm pool $\left(17^{\circ}\right.$ of longitude compared with the observed 


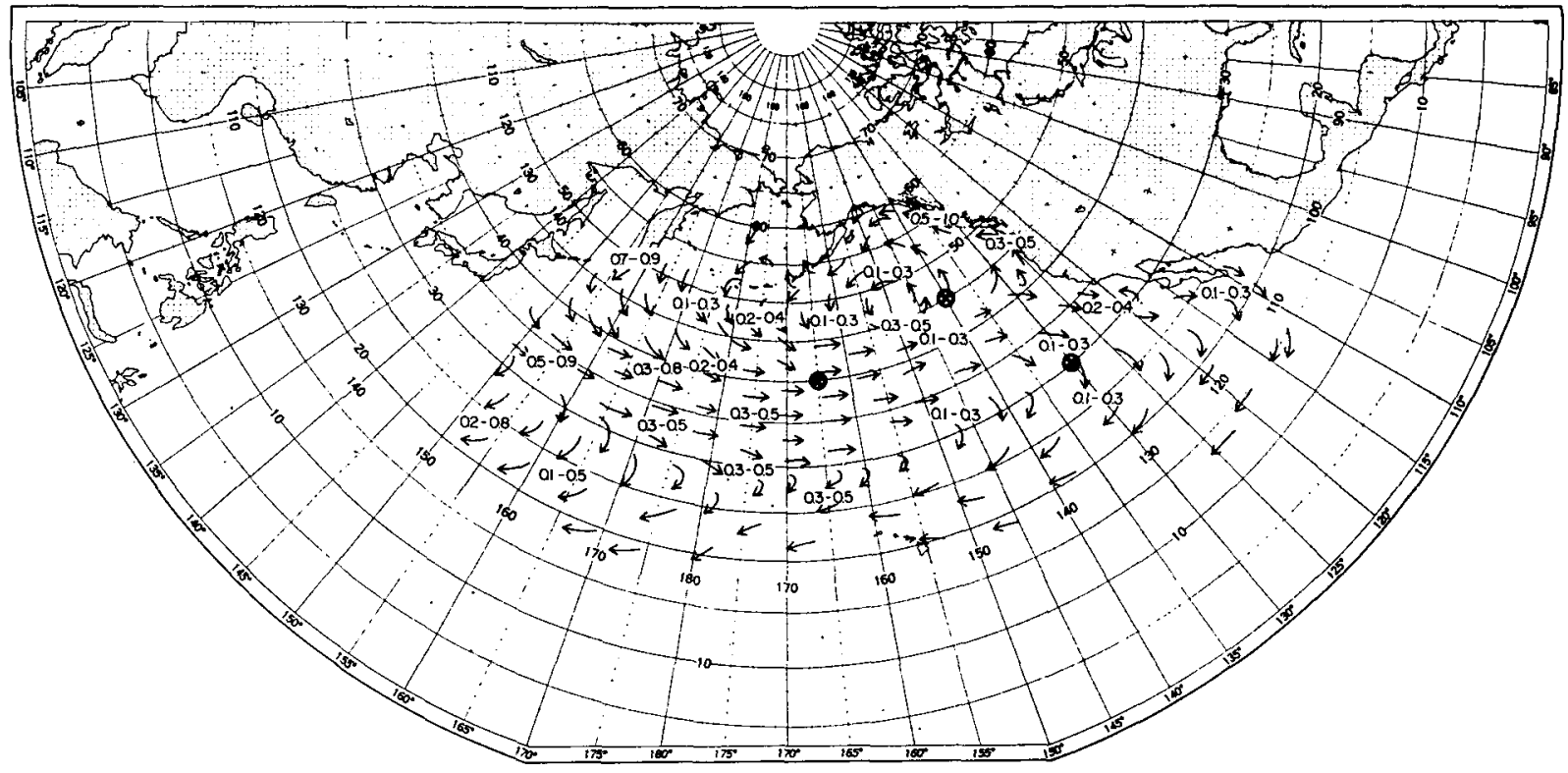

FIg. 8. North Pacific winter surface currents [abbreviated from chart shown in Department of Commerce atlas (1961)].

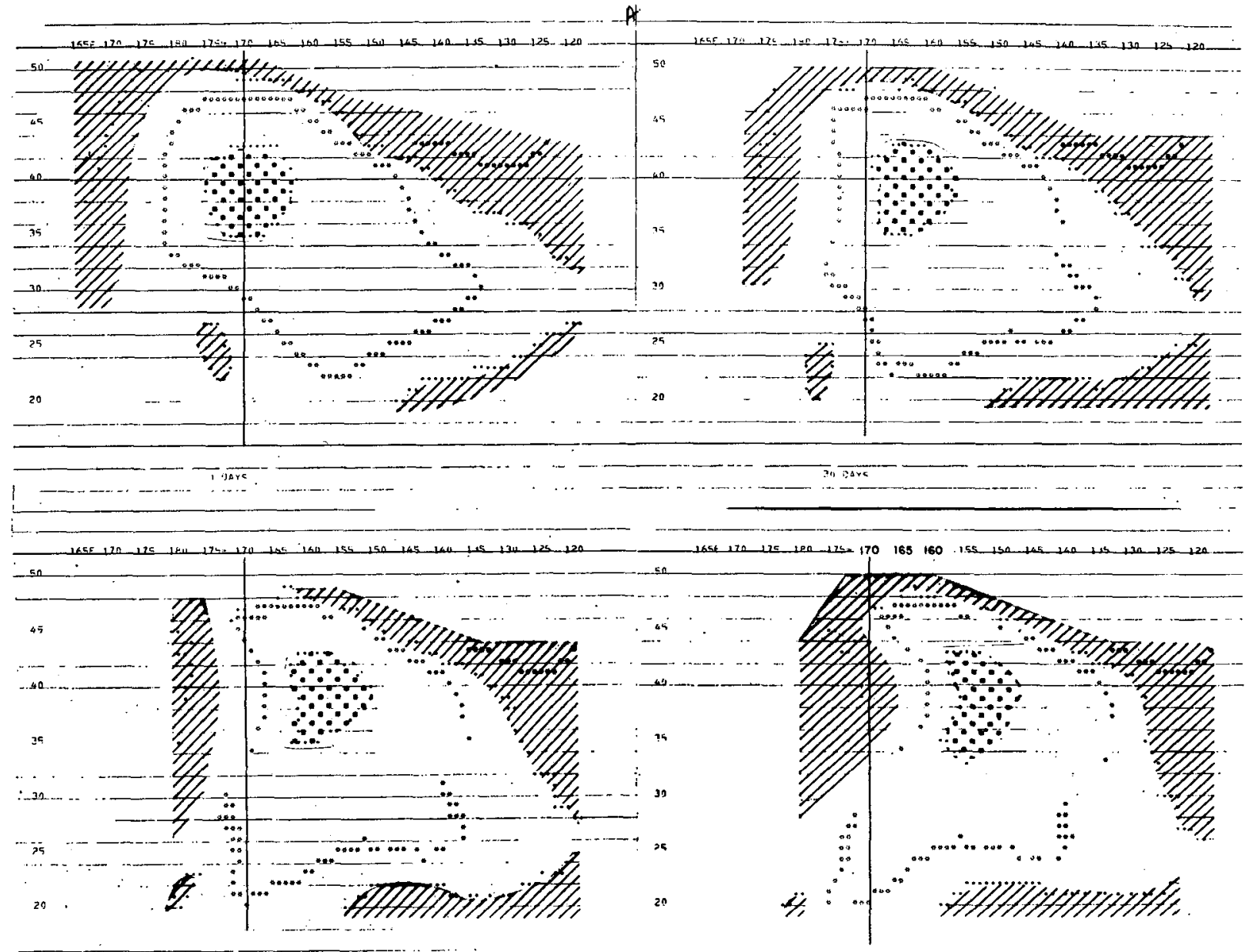

FIG. 9. Initial (a) and predicted (b, $c$, and d) sea-surface temperature anomalies after 30, 60 and 90 days. Hatched areas show anomalies ranging between $-1 \mathrm{~F}$ and $-2 \mathrm{~F}$; stippled areas indicate anomalies $>1 \mathrm{~F}$ (see text for details of construction). Heavy vertical line marks $170 \mathrm{~W}$. 
PREDICTED FOR WINTER (DECEMBER, JANUARY, FEBRUARY) $1911-72$

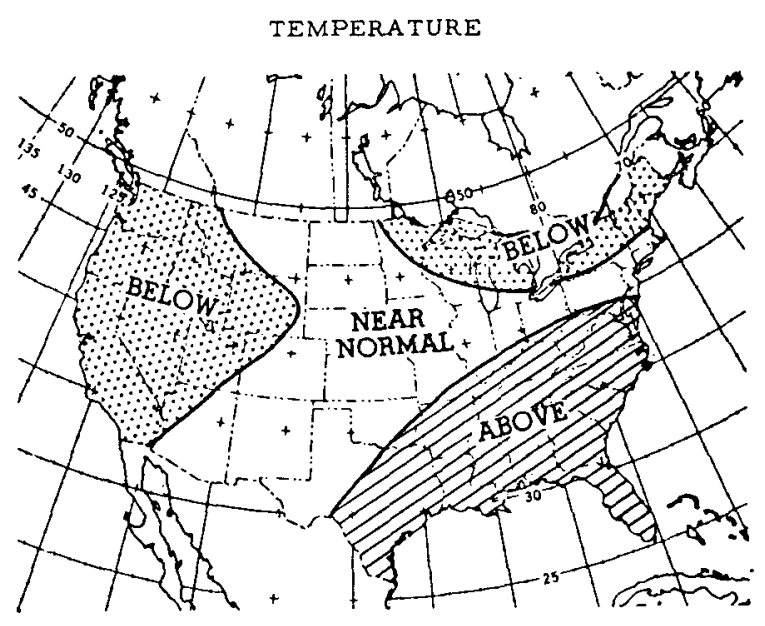

PRECIPITAATION

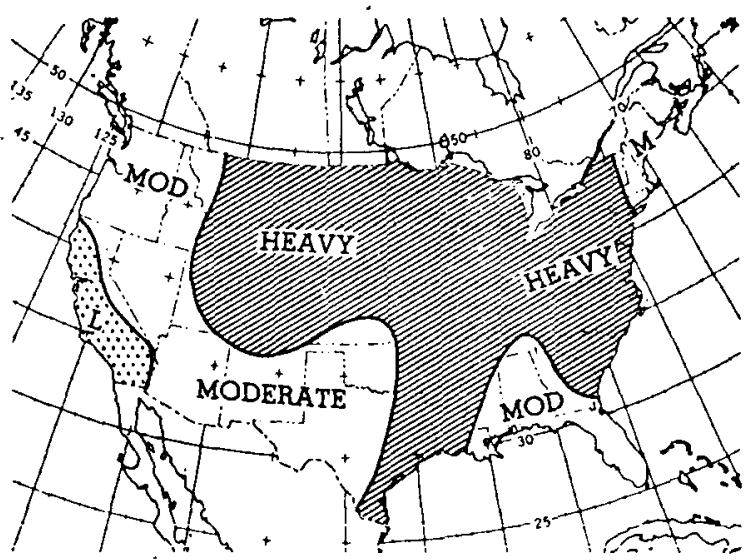

OBSERVED FOR WINTER (DECEMBER, JANUARY, FEBRUARY) $1971-72$

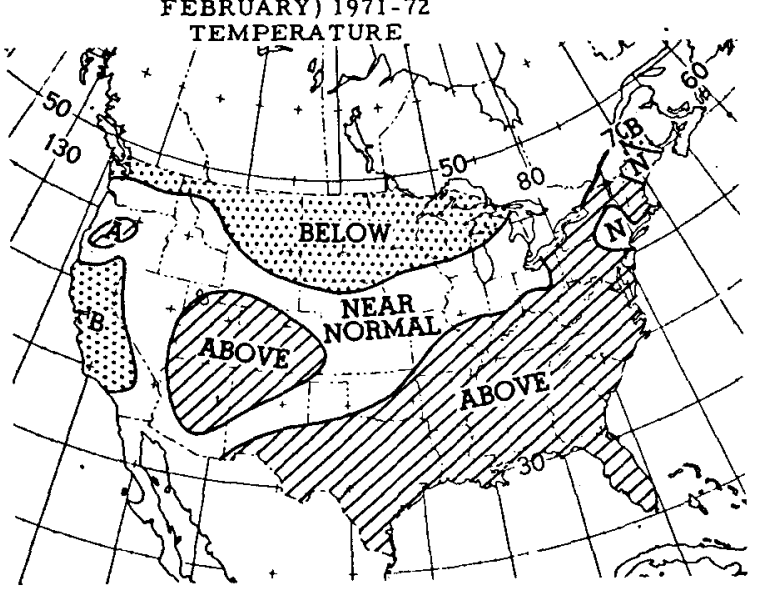

\section{PRECIPITATION}

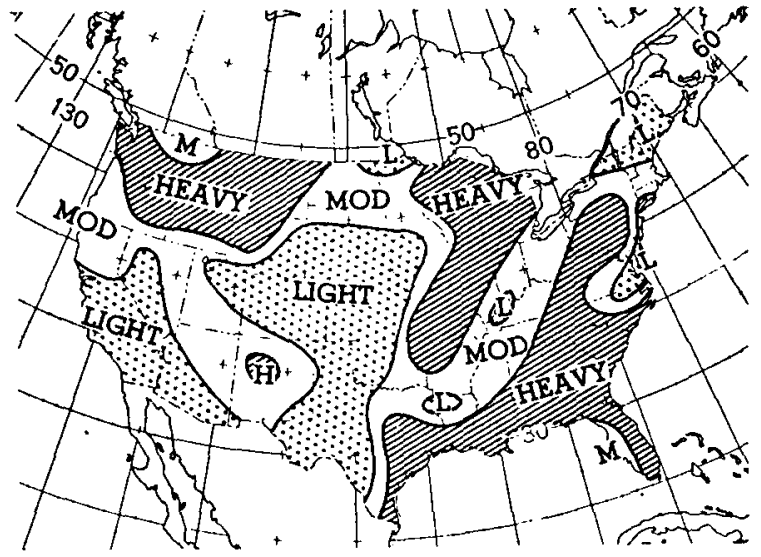

Fig. 10. Observed temperature anomalies (upper) and precipitation patterns (lower) for winter 1971-72; and experimental predictions made on 23 November 1971 by Extended Forecast Division of NOAA. The temperature categories below, near, and above normal are climatologically equally probable, as are the precipitation categories light, moderate, and heavy.

motion of $\left.18^{\circ}\right), 2$ ) the change in orientation of the axis of the warm anomaly area (the zero isopleth from northwest to southeast to essentially north to south), 3) the eastward migration of colder anomalies with the development of a cool bulge behind the warm pool, and 4) the southwestward migration of a small cold pool to about $20 \mathrm{~N}, 180^{\circ}$.

The computations fail to capture the increase in intensity of the warm pool from $1-3 \mathrm{~F}$ and also fail to predict the marked development of cold anomalies from Hawaii eastward and northeastward to the coast. The first of these failures is inherent in any system that simply advects anomalies. Like the advection of vorticity in a moving fluid, this Lagrangian method can only redistribute SST anomalies, not generate or intensify them. The second failure, namely that of capturing the eastern Pacific anomalous cooling, indicates that the climatological mean current velocities of Fig. 8 are much too small to carry the anomalous cold water so far south. Although there was anomalous cooling $(1-2 F)$ in this area brought about by anomalous heat exchange (see Fig. 7), the cooling is not intense enough nor does it span the entire negative anomaly area. I was thus tempted to speculate that during this particular fall and winter the California Current was speeded up relative to its normal strength, thereby generating negative anomalies. This speculation was partly stimulated by the fact that with eastward motion of the warm pool and the resultant strengthening of the west-east SST gradient, the new density field would drive water shoreward and the Coriolis force would then act to strengthen the southward-flowing California Current. Subsequently, it was gratifying to note that in the March 1972 Fishing Information Bulletin (Laurs, 1972), two subsurface temperature sections based on expendable bathythermograph observations were presented which 


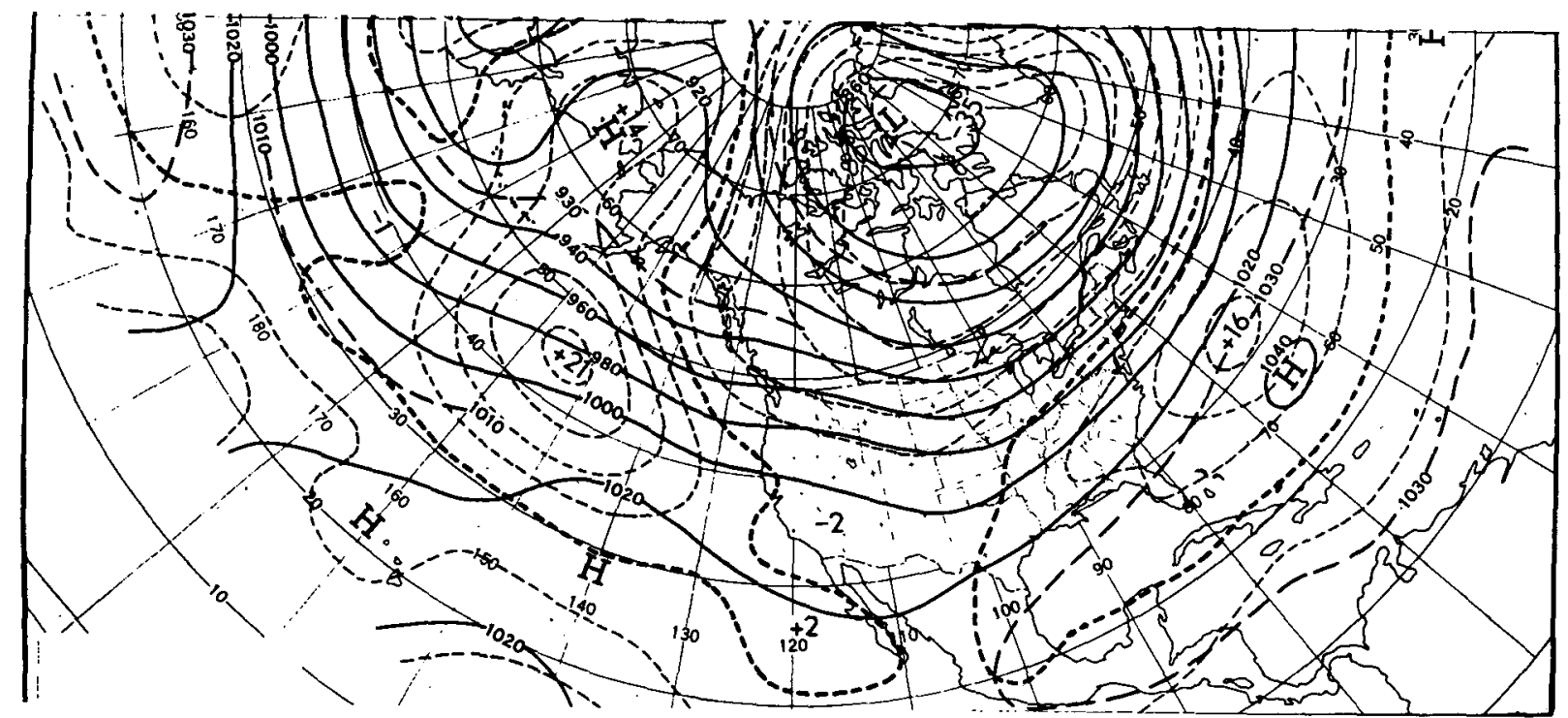

FIG. 11. 700-mb contours (solid) and isopleths of anomaly (broken) for winter 1971-72. Anomaly centers are labelled in tens of feet.

led the authors to the conclusion that the California Current flowing to the southeast across the section "was stronger than in previous years."

Although this advective approach would seem to oversimplify the problem, it does, in fact, suggest that during the 1971-72 winter simple advection around the Pacific gyre played a major part in shaping the SST anomaly pattern. The next questions to be treated involve the possible feedback of the SST patterns on the atmosphere and the evolution of the large-scale atmospheric flow patterns.

\section{Meteorological responses and interactions with the sea}

The winter of 1971-72, as mentioned earlier, was characterized by large weather and circulation anomalies which contrasted with the patterns of the preceding 14 years. The East enjoyed a mild winter, especially during December and January, while parts of the West were colder than normal. These observed abnormalities are shown by a three-class system at the right side of Fig. 10. The corresponding winter precipitation pattern, expressed in three equally-probable classes (light, moderate, heavy) is also shown in Fig. 10. Essentially it was wet in the eastern half of the nation, very dry over the Southwest, and wet in the Pacific Northwest. The dryness over Southern California was so pronounced that the precipitation from January to March totaled only 0.17 inch at San Diego and 0.13 inch at Los Angeles-values that are all-time records and have an expectancy of something like 1 in 1700 .

The seasonal mean $700-\mathrm{mb}$ circulation and its anomaly which led to these patterns is reproduced in Fig. 11, from which it is evident that both the east Pacific and Bermuda highs were appreciably stronger than normal. For example, the 210 -ft anomaly over the east Pacific is about 1.3 times the standard deviation of winter means at this point from a 22-year sample, while the $160-\mathrm{ft}$ anomaly near Bermuda is 2 standard deviations. The latter anomaly and the associated isopleths imply a greater-than-normal flow of air into the East from warm source regions of the Gulf of Mexico, while the Pacific isopleths of anomaly indicate more than the normal deployment of arctic and polar air into the Far West and Northern Plains. The resulting precipitation distribution is also quite consistent in general with this flow pattern, and is, of course, still better specified when the mean winter sea level map (not reproduced) is considered.

The simultaneous increase in both east Pacific and west Atlantic mid-tropospheric heights is a well-known teleconnection (Namias, 1953; O'Connor, 1969). For example, O'Connor's chart showing the probability of sign of 700-mb height anomalies accompanying all cases where a positive center lies at $50 \mathrm{~N}, 150 \mathrm{~W}$ is shown in Fig. 12. It shows that the west Atlantic and east Pacific anticyclones often behave in unison (a full Rossby wavelength apart). Increased southwesterly flow relative to normal is generated in the East and opposing northerly anomalous flow in the West when the east Pacific anticyclone has a strong northward development. ${ }^{2}$

The above treatment is largely a description and interrelationship of weather and circulation phenomenon-not an explanation. A satisfactory physical explanation of the development and maintenance of this winter's east Pacific and west Atlantic anticyclones awaits many years of patient effort in numerical modeling. In the quest for such a solution, I feel that interaction of the atmosphere with the underlying sea plays

${ }^{2}$ C. K. Stidd (1954) has demonstrated that the anomalous components of flow run parallel to lines of probability like those in Fig. 12. 


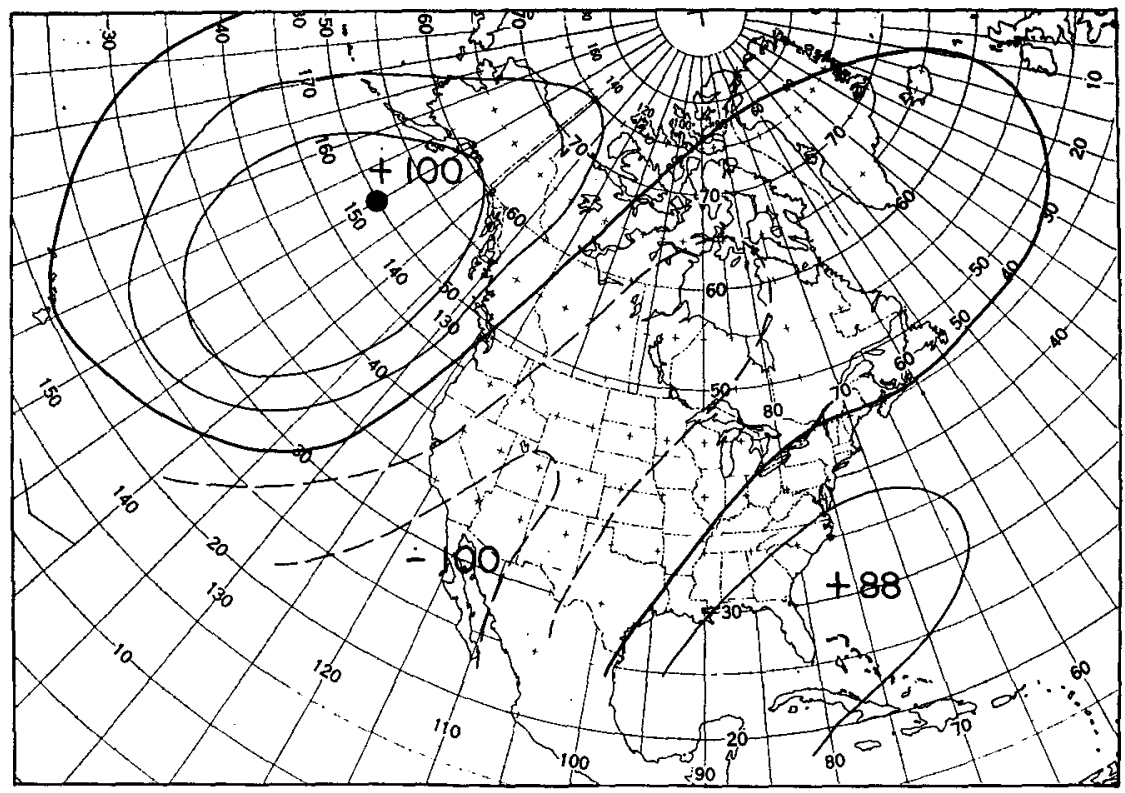

FIG. 12. Isopleths of the probability that the sign of the $700-\mathrm{mb}$ anomaly will be the same as that at $50 \mathrm{~N}, 150 \mathrm{~W}$ (winter). Isopleths are drawn for the three contours $50 \%$ (heavy), $70 \%$ and $90 \%$.

an important role. The remainder of this paper represents an attempt to buttress this idea with numerous observations and statistical indicators.

\section{Modeling experiments in atmospheric fore- casting}

Assuming that there is correlation between largescale atmospheric patterns and the underlying thermal character of the sea surface, now fairly well accepted, it is possible to specify sea-surface temperature patterns by the contemporaneous sea-level pressure patterns or vice versa. Procedures for doing this can be quasiphysical (Clark, 1967) or statistical (Namias and Born, 1972). In the latter case stepwise multiple regression (screening) has been employed to specify sea-level pressure from the contemporaneous pattern of seasurface temperature. The dependent sample of data involved 20 years (1947-66) of data at $5^{\circ}$ intersections over the North Pacific, north of $20 \mathrm{~N}$. We found that by using the first four terms of equations giving sea-level pressure (SLP) anomaly as a function of SST anomaly for winter months, we were able to account for $45 \%$ of the variance. Since SST-anomaly patterns change slowly (high persistence) relative to the atmosphere, one might estimate the SLP pattern for winter 1971-72 by using the fall SST anomaly as input to the regression equations. The resulting "prediction" is given in Fig. 13 which should be compared with the observed in Fig. 14. Note that the pressure distribution (the solid lines) was well estimated. The split Aleutian Iow, the east Pacific high, and the low-latitude trough near Hawaii were all predicted. The predicted anomalies are also correlated with the observed although there are some discrepancies in position and intensity. Perhaps most important is the correct prediction of the strong positive anomaly associated with the ridge extension of the North Pacific high, for this, as shown earlier, had much to do with shaping the downstream circulation pattern over the United States. These equations would, in the long run,

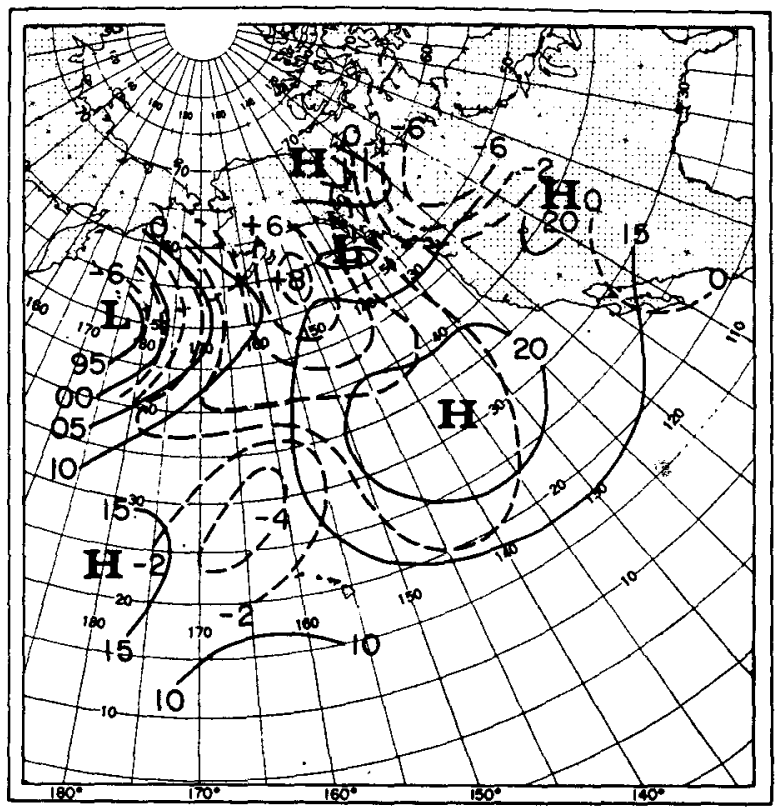

Fig. 13. Objectively predicted sea-level isobars (solid) and isopleths of departure from normal (broken) for winter 1971-72 in 2 -mb intervals (see text for details). 


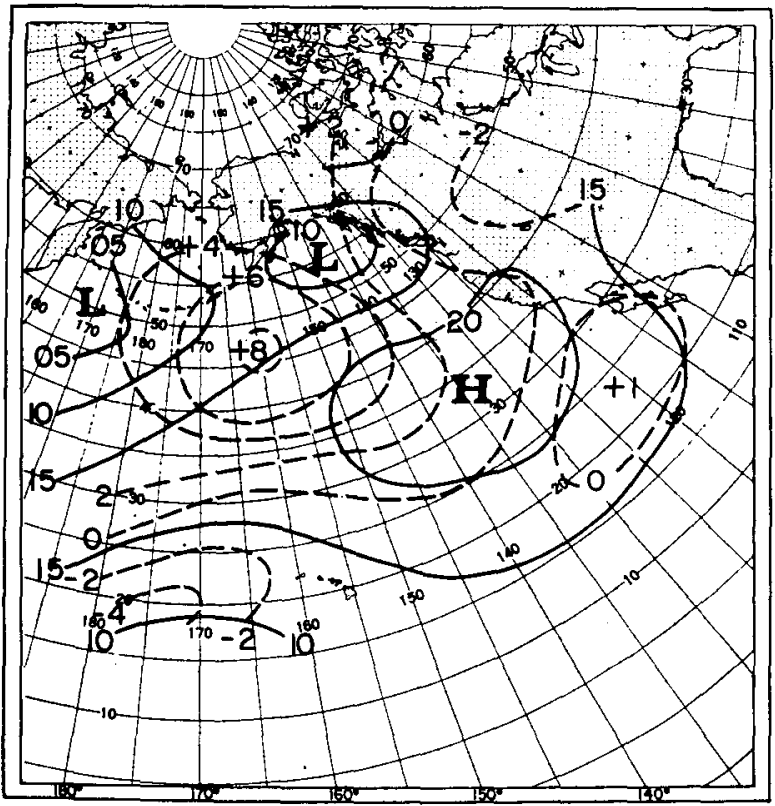

Fig. 14. Observed sea-level isobars (solid) and isopleths of anomaly (broken, drawn for intervals of $2 \mathrm{mb}$ ) for winter $1971-72$.

perform better if the SST winter distribution could be predicted and used as input. In this case the utilization of observed winter SST's (chart not reproduced) did not improve the SLP estimate.

Although the model described and used for this prediction is a statistical one, it implies some macroscale physics. For example, it can be seen from Figs. 2 and 3 that an anomalous west-east SST gradient was observed over much of the eastern North Pacific during both fall of 1971 and the succeeding winter. The input SST data to the SLP prediction calls for a likely atmospheric flow pattern of air transport from the north into the Gulf of Alaska and southward, in order to be consistent with the observed cold anomalies. The warm pool west of the cold water is associated with anomalous east-towest components of surface air flow (in this area, diminished westerlies). These reasonably definitive conclusions arise from earlier studies (Namias, 1970b). But how does the atmosphere recognize or respond to these SST gradients? Perhaps variations in the thermal wind generated by SST gradients constitute part of the mechanism. To estimate the magnitude of this effect, thermal-wind winter $u$ and $v$ components for the 20 year mean (1947-66) and separately for the winter of 1971-72 were computed. These components based on actual sea-level and $700-\mathrm{mb}$ charts, were than compared with estimated thermal-wind anomalies assuming that the SST anomalies extended up to $700 \mathrm{mb}$. The two sets, not shown, correlate well; both methods indicate anomalous northerly thermal winds to the east of roughly $160 \mathrm{~W}$ and anomalous southerly thermal winds to the west. The magnitudes, sometimes exceeding $2 \mathrm{~m}$ $\mathrm{sec}^{-1}$, were as great as the 20-year mean meridional thermal winds. When the SST pattern has a strong west-east gradient, it therefore appears that it can influence the air flow through this thermal-wind mechanism.

A similar experiment was performed by computing the 1971-72 winter $700-\mathrm{mb}$ heights first from normal (20-year average) SLP values plus thicknesses derived from SST anomalies, and second from observed SLP anomalies plus thicknesses derived from normal SST

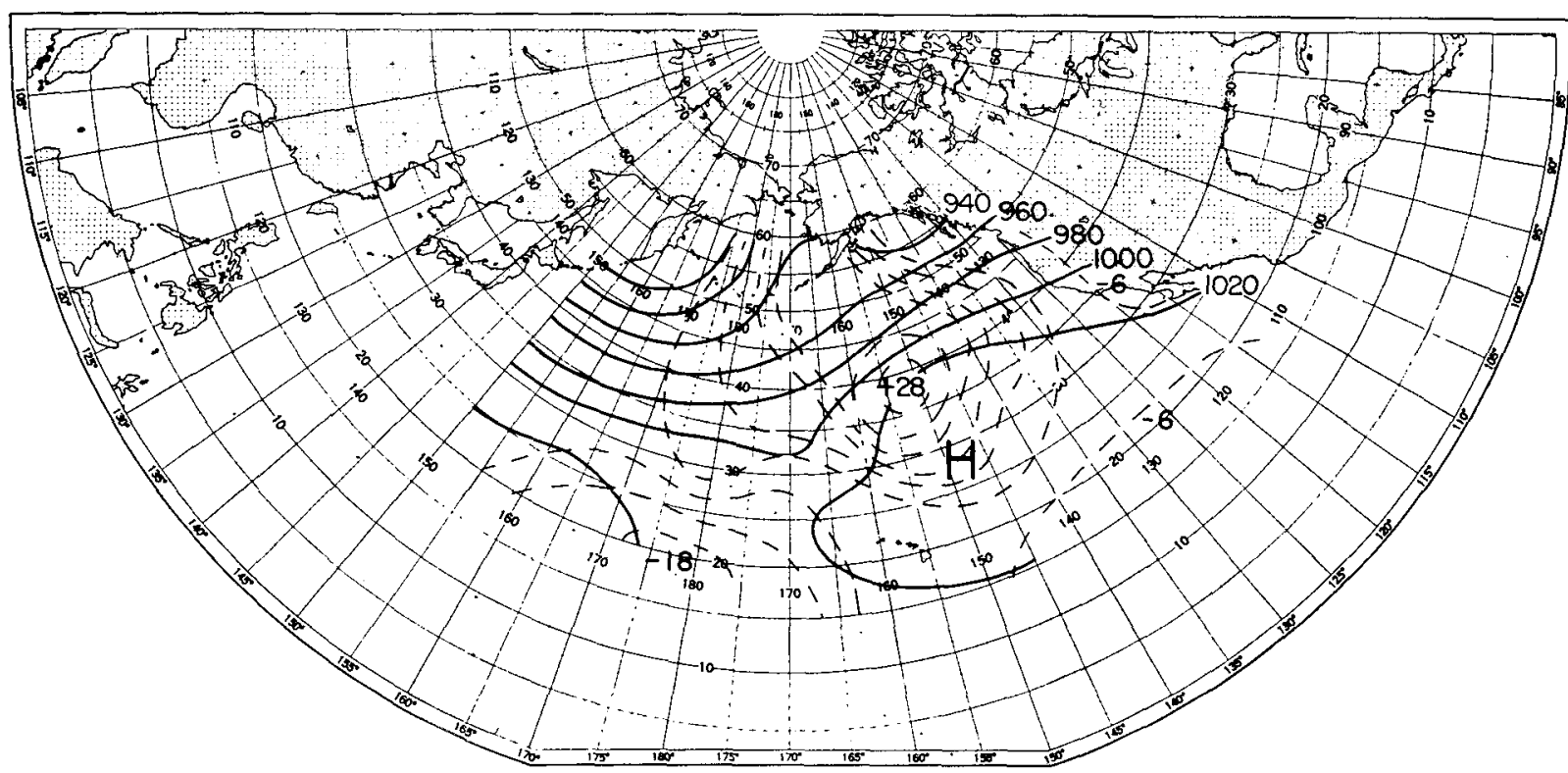

FIG. 15. Optimal prediction of 700-mb contours (solid) and anomalies (broken, in 50-ft intervals) for winter 1971-72. See text for details. 


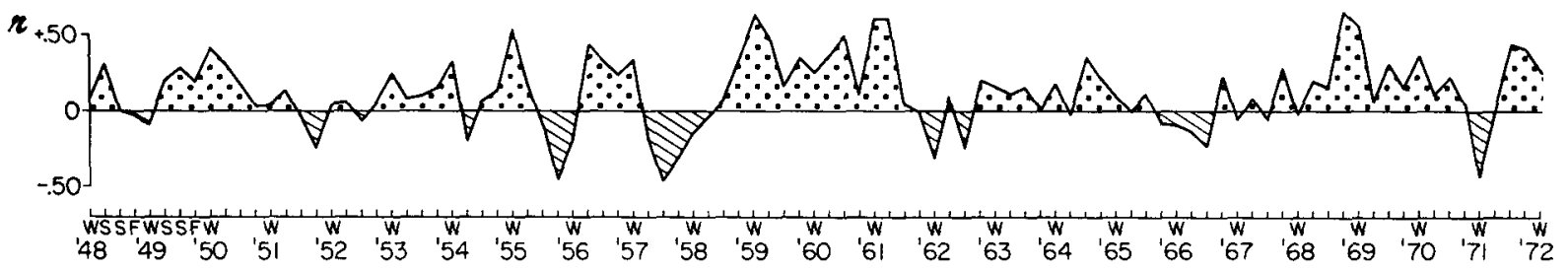

Fig. 16. Correlations of seasonal sea-surface temperature anomaly patterns over the North Pacific from the previous year to the corresponding season of the listed year [updated from Fig. 16 of Namias (1972)].

values. In both cases the computed $700-\mathrm{mb}$ anomalies resembled the observed, with the second computation showing the better resemblance. Finally, a trial $700-\mathrm{mb}$ prediction was made by assuming that the standardized SLP anomalies (anomalies divided by appropriate standard deviations) of fall 1971 were conserved through the winter and that the SST patterns for winter could be predicted by methods indicated earlier in this report. Such a "prediction" is shown in Fig. 15. The success of the principle of conservation of standardized SLP anomalies from fall to winter in this case may imply that airsea interaction processes initiated in the fall of 1971 continued to operate in the following winter and were amplified by the seasonally increased vigor. This trend is indeed indicated by the tendencies in the fall kinematic SST chart (Fig. 6).

While much of the objective work outlined above was done during and subsequent to the winter of 1971-i2, some of the underlying concepts, along with other tools, were employed by the author and his former colleagues at Extended Forecast Division of the National Weather Service, NOAA, as early as November 1971 in making an experimental, seasonal prediction for the ensuing winter. The predictions of temperature and precipitation made at that time $e^{3}$ along with the observed are shown in Fig. 10. The temperature forecast is better than that for precipitation-in conformance with earlier scores indicating the relative success of temperature over precipitation forecasts. The objective predictions described in this paper could have bolstered confidence in the temperature forecast and might have improved the precipitation outlook.

\section{Possible long-period change in climatic regime}

The reversal in a number of meteorologic and oceanic fields in the winter of 1971-72 relative to the prevailing pattern of the preceding 14 years, raises the question of whether a new pattern will characterize the 1970's. The state of the art of forecasting certainly does not permit such predictions at present. There are, however, some interesting facts that point toward a long-range change in the wintertime regime. To reiterate, these are:

1) The pattern of North Pacific SST anomalies showed a strong reversal from the patterns during the

${ }^{3}$ These predictions, completed on 23 November 1971 , were given to the Office of Emergency Planning and appeared in the 13 December 1971 issue of U.S. New's and World Report.
1960 's. The SST anomaly pattern actually began its change in the winter of 1970-71 and the new pattern (warm in central Pacific, cold off the West Coast) was amplified in the winter of 1971-72.

2) Sea-level pressure and mid-tropospheric height anomalies also underwent a reversal over North America and the adjacent oceans during the 1971-72 winter.

3) Temperature anomaly patterns over the United States reflected this circulation change.

Since the above manifestations are interdependent, they cannot be taken as separate pieces of evidence of a decadal change. Perhaps the strongest indicator of change is Item 1, the alternation of SST anomalies over vast areas. This is because a new SST pattern, once generated, has a strong tendency to persist and to reemerge in successive cold seasons (Namias and Born, 1970). An index of persistence of SST anomaly pattern from one season to the same season of the following year is graphed in Fig. 16. This graph was constructed by correlating the SST anomaly patterns for one season with the same season a year later. The basic data were for $5^{\circ}$ squares over the North Pacific for each season for the period 1948 through winter 1972. In all, Fig. 16 represents the end product of about $9 \times 10^{6}$ ship observations.

Except for the occasional negative spikes, Fig. 16 shows that a moderately strong coherence existed between the same seasons of adjacent years. The longest period of persistent negative spikes was observed in 1957-58 when a new SST pattern was emerging. Other negative spikes may have been abortive attempts to break a long period regime-abortive because the changes were not sustained over a long enough period or may have represented shallow rather than deep-water mass changes. The latter condition is more likely if the change occurs between adjacent, non-winter seasons when the thermocline is not as deep as it is in winter. The negative spike identifying a major change between the winters of 1970 and 1971 could mark a break in climatic regime. It is as strong as the 1957-58 spike in terms of intensity (but not duration), and it occurred at the period of deepest thermocline (winter). This break could be transitory and thus not signal a new regime, or it could be a forerunner of a new regime as was the premonitory, negative spike around fall 1955 and winter 1955-56. Mcteorologists and oceanographers 
look forward to the time when more definitive conclusions are possible.

\section{Summary}

The general circulation of the atmosphere over the North Pacific and North America during the 1971-72 winter was strikingly different from that of the preceding 14 winters. The change was associated with equally striking changes in the patterns of North Pacific sea-surface temperature anomaly. The 1971-72 pattern (cold water off the west coast and warm water in the east central Pacific) started generating during fall and developed into the winter pattern largely by advective transport around the North Pacific gyre. Kinematic computations made from fall SST anomalies indicate a slow orderly development from fall to winter, and Lagrangian computations using normal surface currents as carriers of anomalies seem to have captured the essential character of the winter pattern. Heat exchange appears to have played a small (and at times opposed) role in the development of the winter SST anomalies, except in the area between Hawaii and California, but even here the speeded-up California Current played a role in generating cold anomalies. This case is special because the isopleths of SST anomaly were largely orthogonal to the main currents of the North Pacific gyre.

The winter SST-anomaly pattern imposed demands on the overlying atmospheric circulation. The observed responses were indicated in advance by the application of multiple regression (screening) formulae, developed from a previous 20 -year data sample, specifying sealevel pressure patterns from sea-surface temperature patterns. The physical mechanism of feedback from sea to air, in this case, appears to have been through hydrostatic tilting of isobaric surfaces due to anomalous, differential heat supply from the underlying water.

Additional "predictions," of the seasonal atmospheric circulation, involving the conservation of standardized anomalies as well as SST influences on the overlying air, were shown to have skill.

Finally, the 1971-72 winter was contrasted to the regime of the preceding 14 years. The contrasts showed up in 1) a United States temperature pattern (warm in the east but cold in the west in 1971-72, opposite to that of the preceding years), 2) North Pacific SST patterns (cold off the West Coast, warm in east central North Pacific vs the opposite in earlier years), and 3) strong east Pacific anticyclone in 1971-72 vs weak in the 1960's.

These factors, while interdependent, nevertheless imply the possibility of a new climatic regime for the 1970's. The strongest implication may lie in the SST pattern change which is shown to be persistent for many seasons and even years after a break.
Acknowledgments. In the research associated with this paper I wish to thank Charles K. Stidd and Robert Born for stimulating discussions and editorial help, John Faust for programming, Fred Crowe for drafting, Mrs. Maren Malhas and Mrs. Madge Sullivan for charting assistance, and Miss Leslie Price for typing the manuscript.

This work was supported by the Office of Naval Research under Contract N000-14-69-A-0200-6006 through the Marine Life Research Program at Scripps Institution of Oceanography.

\section{REFERENCES}

Clark, N. E., 1967 : Report on an investigation of large-scale heat transfer processes and fluctuations of sea-surface temperature in the North Pacific Ocean. Ph.D. thesis, Massachusetts Institute of Technology, $148 \mathrm{pp}$.

Department of Commerce, 1961 : Climatological and Oceanographic Atlas for Mariners. Washington, D. C., Gov't Printing Off., $159 \mathrm{pp}$.

Dickson, Robert R, 1972: Weather and circulation of December 1971, return to persistent temperature regime. Mon. Wea. Rev., 100, 239-244.

Johnson, J. H., G. A. Flittner and M. W. Cline, 1965: Automatic data processing. Programs for Marine, synoptic radio weather reports. U. S. Dept. of the Interior, Fish and Wildlife Service, Spec. Science Reprint, Fisheries No. 503.

Laurs, R. M., 1972: Fishing Information Bull., March. National Marine Fisheries Service, Southwest Fisheries Center of La Jolla, Calif., No. 3,17 pp.

Namias, Jerome, 1953: Thirty-day forecasting-A review of a ten year experiment. Meteor. Monogr., 2, No. 6, 83 pp.

- 1970a: Climatic anomaly over the United States during the 1960's. Science, 170, 741-743.

- 1970b: Macroscale variations in sea-surface temperatures in the North Pacific. J. Geophys. Res., 75, 565-582.

_-, 1972: Large-scale and long-term fluctuations in some atmospheric and oceanic variables. Proc. 20th Nobel Symposium, Gothenburg, Sweden, Almquist and Wiksells Boktryckeri, Uppsala (in press).

- - and R. M. Born, 1970: Temporal coherence in the North Pacific sea surface temperature patterns. J. Geophys. Res., 75, 5952-5955.

— and - 1972: Empirical techniques applied to large-scale and long-period air-sea interactions, a preliminary report. S. I. O. Reference Series 72-1, University of California-San Diego, Scripps Institution of Oceanography, $47 \mathrm{pp}$.

O'Connor, J. F., 1969: Hemispheric teleconnections of mean circulation anomalies at $700 \mathrm{mb}$. Washington, D. C., ESSA Tech. Rept. WB10, 103 pp.

Petterssen, S., 1956: Weather Analysis and Forecasting, Vol. 1. New York, McGraw-Hill, 428 pp.

Robinson, M. K., and R. A. Bauer, 1971: Atlas of Monthly Mean Sea Surface and Subsurface Temperature and Depth of the Top of the Thermocline North Pacific Ocean. Monterey, Calif., Fleet Numerical Weather Central, $96 \mathrm{pp}$.

Stidd, C. K., 1954: The use of correlation fields in relating precipitation to circulation. J. Meteor., 11, 202-213.

Taubensee, Robert E., 1972: Weather and circulation of February 1972, warm and continued dry in the far southwest. Mon. Wea. Rev., 100, 411-416.

Wagner, A. James, 1972: Weather and circulation of January 1972 , a month with record strong mid-latitude westerlies. Mon. Wea. Rev., 100, 322-328. 